\title{
ARTÍCULO OPINIÓN
}

LA RED NACIONAL DE LABORATORIOS DE SUELOS REFUERZA CALIDAD PARA PRODUCTORES ECUATORIANOS

En octubre del año 2000, en el VII Congreso de la Sociedad Ecuatoriana de la Ciencia del Suelo (SECS) nace como institución de apoyo la Red de Laboratorios de Suelos del Ecuador - RELASE, acogiéndose a los estatutos aprobados por la SECS mediante acuerdo ministerial No. 3487 del 5 de febrero de 1970. La RELASE tiene como objetivos brindar a los productores un servicio que cumpla con los estándares de calidad para el estudio de suelos, foliares y aguas, así como también homologar e implementar metodologías de análisis para la determinación de nutrientes en dichas matrices y establecer planes de mejora en los diferentes laboratorios agrícolas del país que se encuentran conformando la Red.

La RELASE actualmente se encuentra bajo la Coordinación de la Agencia de Regulación y Control Fito y Zoosanitario - AGROCALIDAD, por medio del Laboratorio de Suelos, Foliares y Aguas, el mismo que realiza anualmente ensayos de intercomparación y aptitud en las matrices de suelos y tejidos vegetales con el fin de medir el desempeño de los laboratorios que conforman la Red.

En el año 2017 se realizó la última reunión para analizar los resultados de los ensayos de intercomparación con la participación de representantes de la SECS, AGROCALIDAD, INIAP (Santa Catalina, Litoral Sur, Pichilingue, Austro, Amazonía), MAG, Universidad Central del Ecuador, Universidad Nacional de Loja, Universidad Estatal Amazónica, Universidad Técnica Equinoccial Sede Santo Domingo, Universidad Técnica de Ambato, Escuela Politécnica del Carchi, Universidad Nacional de Loja, Universidad Central del Ecuador, Ingenio San Carlos, CINCAE y NEMALAB. En esta reunión se establecieron los siguientes compromisos: 1) Verificar el estado actual de los laboratorios de suelos del Ecuador, 2) Establecer la nueva fecha del próximo ensayo de intercomparación, 3) Generar un plan dirigido a la acreditación de los laboratorios con base en los criterios de la Norma ISO/IEC 17025:2005, 4) Coordinar a futuro acciones con el Servicio de Acreditación Ecuatoriano (SAE); esta última con el fin de que la RELASE trabaje sus pruebas de intercomparación en base a la Guía ISO/IEC 17043:2010, ya que dicha norma internacional especifica los requisitos generales para la competencia, el desarrollo y la operación de los programas de ensayos de aptitud.

Así mismo se creó un comité para la actualización de las metodologías de análisis, formado por los técnicos de AGROCALIDAD, INIAP-Litoral Sur, INIAPSanta Catalina y CINCAE. Esta comisión presentará la primera guía impresa de métodos para análisis de laboratorio en la siguiente reunión a realizarse en el CINCAE en el mes de mayo del presente año.

Con lo expuesto anteriormente, en la RELASE se está fomentando el brindar servicios de calidad hacia el sector agrícola del Ecuador, mejorando continuamente el desarrollo de nuestros procesos y de esta manera romper el paradigma que en nuestro país no existen laboratorios de diagnóstico para el estudio de nutrición vegetal con estándares de calidad que puedan competir internacionalmente y sustentar datos con fines investigativos.

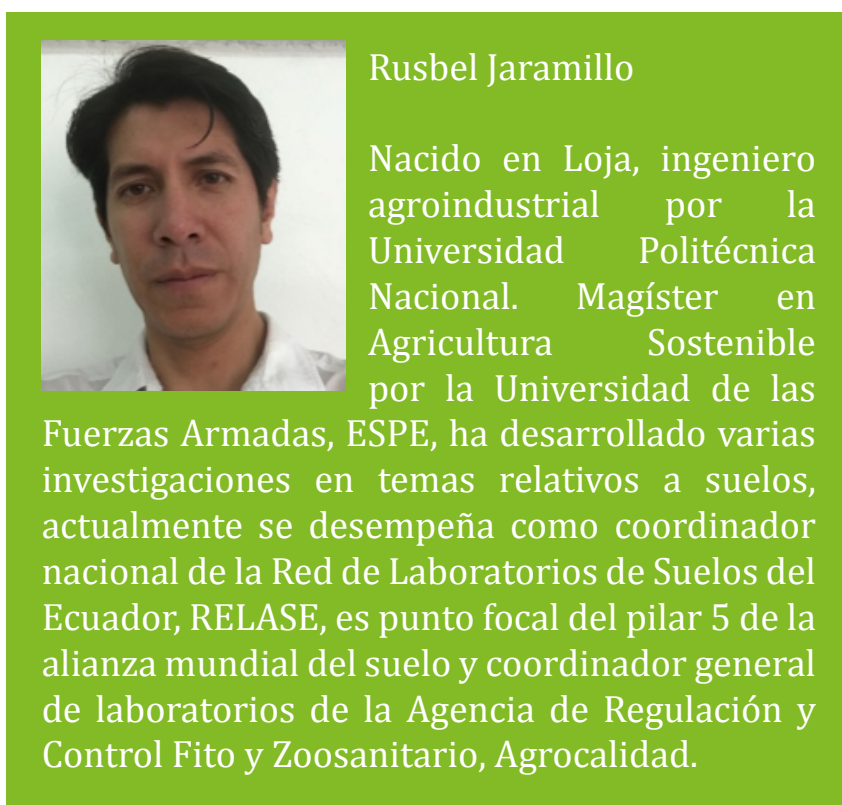

Rusbel Antonio Jaramillo Chamba 